\title{
The Impact of Digital Advertising Message toward Consumer Responses based on The Facet Model of Effects (Study on WWF Indonesia's Instagram Advertising FaceApp Version on @wwf_id)
}

\author{
Sylvie Nurfebiaraning ${ }^{1}$, Lu'lu Mutia ${ }^{2}$, Suci Indah Wulandari ${ }^{3}$ \\ \{sylvienurfebia@gmail.com¹, lulumutiaa@gmail.com²,wulandarisuci843@gmail.com ${ }^{3}$ \} \\ Universitas Telkom, Bandung, Indonesia ${ }^{1,2,3}$
}

\begin{abstract}
The knowledge about plastic waste dangers to the environment is very important for the audience. One of the forms of persuasive communication is advertising, consist of visual elements like logos, colors, layouts, photographs and texts. Advertising messages can affect consumer responses based on six factors. The Facet Model of Effects consist of perception, emotion, cognition, association, persuasion, and behaviour. WWF Indonesia, is the nonprofit organization engaged in environmental conservation. WWF Indonesia through their Instagram social media account@wwfid, provides knowledge about plastic waste. WWF Indonesia advertisement The FaceApp version is one of WWF Indonesia campaign to reduce plastic waste. In this advertisement there are three pictures of plastic waste with smiley face on it and the text is "FaceApp doesn't work on plastic". It means that plastic waste cannot change just like a face using FaceApp, an artificial intelligence-based photography application that was viral on social media. This research was conducted using quantitative research method by distributing questionnaires to 100 respondents through non-probability sampling techniques. The data analysis technique used is a simple linear regression to prove the hypothesis that there is a significant impact of digital advertising messages (X) toward consumer responses based on six factors of The Facet Model Effects perception (Y1), emotion (Y2), cognition (Y3), association (Y4), persuasion (Y5), and behavior (Y6). Based on the results, X-Y1, X-Y2, X-Y4, XY6 influence each other or $\mathrm{H} 1$ is accepted. $\mathrm{X}-\mathrm{Y} 4$ has the highest value which is $60.5 \%$. It means there is significant influence of advertising message $(\mathrm{X})$ towards association facet (Y4). However, X-Y3 and X-Y5 are not involved in hypothesis testing because the data are not normally distributed.
\end{abstract}

Keywords: Digital Advertising Message, Environment, Consumer Responses.

\section{Introduction}

The advertising industry is one of the digital industries in Indonesia that always developed. The Ministry of Industry said that the national digital industry projection grows above 11 percent/year due to the support of the connected internet throughout Indonesia. The growth of digital advertising because of internet use in Indonesia, exceeds half of the total population of 265.4 million people. From Global Digital Ad Trends Report 2019, PubMatic predict that the digital advertising market grow rapidly and Indonesia's digital advertising expense reach $\$ 2.6$ billion or 26 percent better compared to last year [1]. 
Digital trends have completed the advertising process to provide information, persuade, educate, entertain and influence consumer response toward provided advertisement content. Advertisers must be creative in determine the media, so the advertising messages can be received and right on target. Creativity is the foundation of advertising and it has to follow digital trends that consumed by the audience. So, that the audience easier to make decisions when they are viewing advertisements through their smartphones.

Advertising through social media is complementary to the overall advertising strategy and it utilized by WWF Indonesia in campaigning and broadcasting environmental education, strengthening communities and increasing public awareness. Based on pre - research results held by author with 75 respondents, 53.3\% of them knew WWF Indonesia. The result shows that WWF Indonesia is the most known environmental organization. One of the campaigns that WWF Indonesia has is \#LupainPlastik (\#ForgetPlastics) with expectations to persuade the audience to reduce the use of plastic waste in everyday life. $98,7 \%$ respondents understand the dangers of plastic waste and $89.3 \%$ participated in reducing the use of plastic waste.

Instagram active users have been increasing since 2013 and it grow rapidly year by year. At the beginning of 2018 Instagram active users reach 1.000 million people all over the world [2]. Instagram active users that are always increasing is the reasons for brands to use social media in advertising. Instagram is also able to combine text and graphics so that it can be easier to convey a message to audience. This also happen to WWF Indonesia which use Instagram to advertise WWF Indonesia advertisement FaceApp version with the ad messages "Sekarang atau 50 tahun lagi... ku masih akan tetap seperti ini (Now or 50 years from now ... I will still be like this) and it end with the message "\#FaceApp doesn't work on plastic! So, change your lifestyle not your face". The advertisement message which educate the audience to reduce the use of plastic waste because it is dangerous and difficult to decompose. Advertising characteristic is persuasive because advertising messages try to build, strengthen, or change perception, attitude, build opinion, touch emotion or elevate belief. This is related with the opinion of Littlejohn that persuasion is an attempt to change thoughts and actions by manipulating motives towards the goals that have been set [3]. Thus, WWF Indonesia ad FaceApp version is expected to persuade the audience to have a positive response toward the advertisement message.

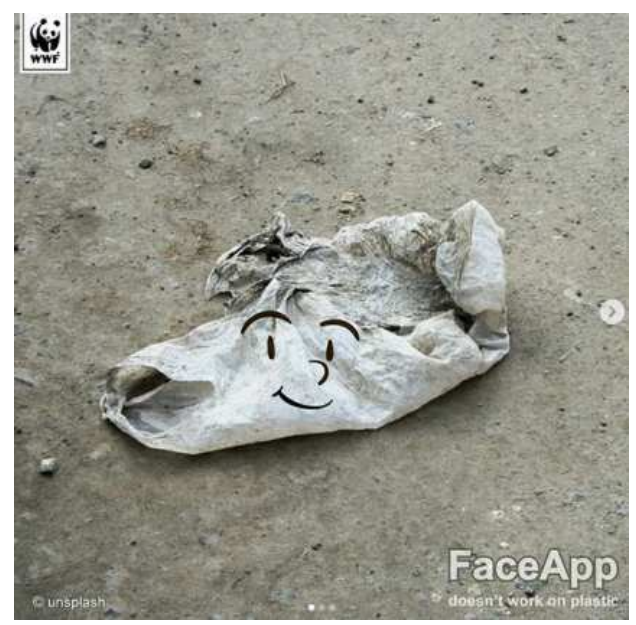

Fig. 1. WWF Indonesia ad FaceApp version. 
FaceApp version of WWF Indonesia ad is related to reducing plastic waste in Indonesia which the topic is still being promoted. The use of plastic waste in this era is very rapid and causes humans to have a higher level of dependence on plastic. The plastic waste takes 1000 years to decompose completely by soil, but the plastic particles still remain and it will pollute the soil and groundwater. In addition, Forest Digest Magazine by forestdigest.com, "Bumi Kian Merana" special edition April-June 2019 p. 14, stated that the consumption of plastic is a human activity that really affect nature. Since 1980, plastic pollution has float in the sea water and now it increases ten times than before. Which threaten 86 percent of sea turtle, 44 percent of seabirds and 43 percent of sea mammals.

Hikmat Ramdan as a natural resource's expert and lecturer at the Faculty of Biological Sciences, Bandung Institute of Technology. He stated that the plastic waste problem is everybody's problem. They consume and produces plastic waste in everyday life. He also said that awareness of plastic waste is still relatively low. Hikmat Ramdan also give the opinion toward advertisement in social media. The ad can be hard to maintain its existence because it does not use the message that can affect consumer subconscious and change consumer response positively. So, the frequency of the communicator and communicant in advertising is not yet synergy. This can be proved by audience or consumer attitude when they are littering and do not understand the impact of it.

WWF Indonesia has a role in campaigning \#LupainPlastik (\#ForgetPlastic) through WWF Indonesia advertisement FaceApp version. The advertisement will be the object of this research. This ad also consists of photos, logos, and text/script that can be studied/researched.

Therefore, this research wants to find out the effect of WWF Indonesia (FaceApp version) messages which is use one sided structure and fear appeal message toward consumer responses based on six factor of The Facet Model of Effects which contain perception, emotion, cognition, association, persuasion and behavior. The research hypothesis follows:

$H_{0} 1$ : There is no significant effect of advertising message $(X)$ towards perception (Y1).

Hil: There is a significant effect of advertising message (X) towards perception (Y1).

$H_{0}$ 2: There is no significant effect of advertising message $(X)$ towards emotion (Y2).

Hi2: There is a significant effect of advertising message $(X)$ towards emotion (Y2).

$H_{0}$ 3: There is no significant effect of advertising message $(X)$ towards cognition( $\left.Y 3\right)$.

Hi3: There is a significant effect of advertising message $(X)$ towards cognition (Y3).

$H_{0} 4$ : There is no significant effect of advertising message $(X)$ towards association (Y4).

Hi4: There is a significant effect of advertising message (X) towards association (Y4).

$H_{0}$ 5: There is no significant effect of advertising message (X) towards persuasion (Y5).

Hi5: There is a significant effect of advertising message (X) towards persuasion (Y5).

$H_{0} 6$ : There is no significant effect of advertising message $(X)$ towards behaviour (Y6).

Hi6: There is a significant effect of advertising message (X) towards behaviour (Y6).

\subsection{Advertising Message}

Message consist the information or meaning that hopes to convey. It can be verbal, nonverbal or through symbol [2]. How message is delivered is very important because it determine the effectiveness of the message. Advertiser should have a skill to make or decide the content of messages, how the information will be structure and what kind of message appeal that will be used.

Marketing communication usually consist of message points. Message structure communicate these points effectively so it can attract the audience. One of the message structures is massage side. 
One sided message mention only positive attributes or benefit, two sided message present both good and bad points [4]. Most of advertiser use one sided message which only deliver positive and present the benefit of the product.

Advertiser should determine the right message appeal for the advertisement. Some ads are design to appeal rational or logical aspect. The others are design to appeal feeling to evoke the emotion reaction. One of them is fear appeal.

Fear is an emotion response to a threat that expresses or at least implies some sort of danger [4]. Fear appeal will arouse the audience to take steps to remove the threats. For instance, campaign to stop and reduce plastic waste due to threats toward health and environment.

\subsection{The Facet Model of Effects}

The facet model of effects is a six factor model that is useful both in setting objectives and evaluating the effectiveness of brand communication [5]. The advertisement will be effective if it is meet the facet model of effects that have six type of consumer response. There is perception, emotion cognition, association, persuasion and behaviour.

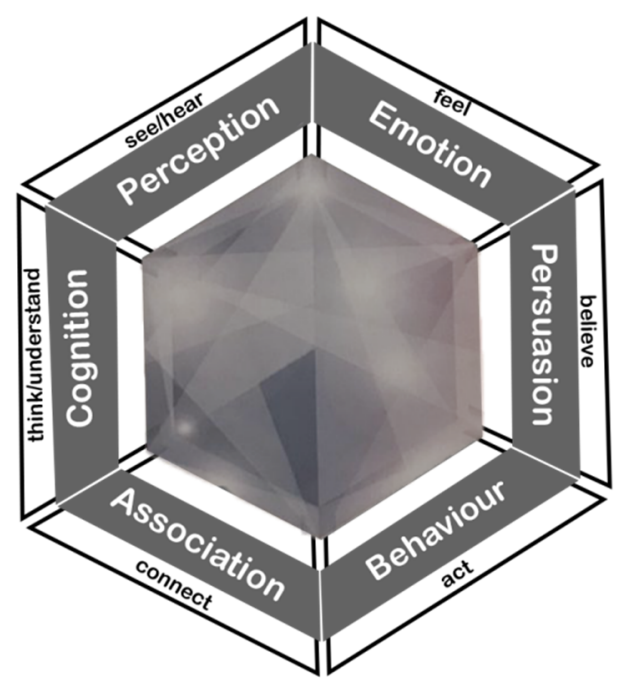

Fig. 2. The Facet Model of Effect.

Perception is the process with the audience received information through five senses [5]. The advertisement can be effective, first of all it has to get noticed. The audience at least has to be seen or heard the ad even in the perception is minimal and largely below the level of the awareness. There are several key factors that drive perception. The key factors are exposure, selection, attention, interest, relevance, curiosity, awareness and recognition.

Emotion is the sign of effective advertisement. The term of affective (emotion) describe as something that stimulates wants, touches the emotions, establish a mood, creates liking and elicits feelings [5]. If individuals like the ad, the message that deliver by ad will be effective and easy to deliver. The factors that drive emotion are wants $\&$ desire, excitement, feeling, liking and resonance. 
Cognition refers to how consumers search and make sense of information as well as how they learn and understand something [5]. The emotion facet will create emotional appeal toward consumer. The cognitive facet will create rational appeal. In this level the consumer has the awareness for a brand and fully understand the context of the message. The key factors that drive this facet are need, cognitive learning, comprehension, differentiation and recall.

Association facet is communication technique through symbols [5]. The goal is to use symbolic connection to define a brand. The key factors of association are symbolism, conditional learning and transformation.

Persuasion facet is the conscious intent on the part of the source to influence or motivate the receiver of a message to believe or do something [5]. Persuasive communication makes or change consumer attitude towards brand. Attitude can persuade the audience to do something. It can be in positive, negative or neutral form. For example, negative attitude toward smoking prevent teenagers to try to smoke cigarettes. The key factor of persuasion are motivation, influence, involvement, engagement, conviction, preference and intention, loyalty, believability and credibility.

Behaviour facet involve in several type of action such as trying or buying a product. The goal is to make the audience to do something such as trying or buying product, click on a website or signing up in environmental campaign. Several factor that drive behaviour facet are mental rehearsal, trial, buying, contacting, advocating and referrals and prevention.

\section{Research Method}

Paradigm used in this study is positivism. According to Neuman, positivist view social science as combining deductive logic with exact empirical observation through individual behavior. Furthermore, positivist aim to discover and confirm a set of probabilistic causal laws that can be used to predict general patterns of human activity [6]. The research method used in this study is quantitative. Quantitative characteristic, the researcher begin the study by hypothesis testing, the concepts taken are in the form of clear and measurable variables, taken before preparation before data collection and each measurement meets the standards set [6].

The study used survey as data collection technique through questionnaire to 100 respondents who saw WWF advertisement FaceApp version on Instagram @wwf_id with an error level of $5 \%$. The population is homogeneous because the source elements have same character and need to have sample, stated in Miles and Huberman [7]. The type of sample is non-probability sampling-random; it means that every population member has not same chance to be chosen as sample. It based on same criteria's which are follower@wwf_id and have ever seen the WWF Indonesia's Instagram Advertising FaceApp version.

This study used simple linear regression. Advertising massage is independent variable (X) measured based on one sided massage and fear appeal. While dependent variable (Y) consist of perception variable (Y1), emotion variable (Y2), cognition variable (Y3), association variable (Y4), persuasion variable (Y5), and behavior variable (Y6) [8].

\section{Result and Analysis}

Based on result with 100 respondents, at most 70 people were female, 78 people aged 17 to 22 years and 50 people worked as students. WWF advertisement FaceApp version attract 
respondent because the ad made the respondents curious, so they eager to know the meaning of the message that conveys by the ad. After they seen the ad $62,3 \%$ respondents sign up in reduce plastic waste and $60,4 \%$ had been apply the message that convey by the ad in daily life. Furthermore, 68-71 people had been persuaded families, friends, co-workers to limit the use of plastic waste.

Table 1. Respondents Data

\begin{tabular}{|c|c|c|}
\hline No & Respondent & Number \\
\hline \multirow[t]{3}{*}{1} & Gender & \\
\hline & Male & 30 \\
\hline & Female & 70 \\
\hline \multirow[t]{4}{*}{2} & Age & \\
\hline & $17-22$ yo & 78 \\
\hline & $23-28$ yo & 21 \\
\hline & $35-40$ yo & 1 \\
\hline \multirow[t]{7}{*}{3} & Profession & \\
\hline & Student & 2 \\
\hline & College Student & 50 \\
\hline & Private Employees & 17 \\
\hline & Government Employees & 3 \\
\hline & BUMN & 3 \\
\hline & Others & 25 \\
\hline
\end{tabular}

Source: Processed Research Data, 2019.

WWF advertisement FaceApp version messages aim to give positive response which the impact targeted audience behaviour. Based on the data, respondent is mostly in the age of 17 22 years old. They included in millennial generation which understand that the ad illustrates the danger of plastic waste and it cannot recycle. Furthermore, 68 people were worried to use plastic and $52 \%$ people tried to stop using plastic because the influenced of the ad message that convey by WWF Indonesia. The result of simple linear regressions is:

Table 2. Results of Linear Regression Data

\begin{tabular}{lcccc}
\hline Variable & Sig. & $t$ & $\mathrm{R}_{\text {square }}$ & Coefficient of Determination \\
\hline $\mathrm{X} \& \mathrm{Y}_{1}$ & 0,00 & 7.931 & 0.391 & $39,1 \%$ \\
$\mathrm{X} \& \mathrm{Y}_{2}$ & 0,00 & 9.355 & 0.472 & $47,2 \%$ \\
$\mathrm{X} \& \mathrm{Y}_{4}$ & 0,00 & 12.248 & 0.605 & $60,5 \%$ \\
$\mathrm{X} \& \mathrm{Y}_{6}$ & 0,00 & 10.651 & 0.537 & $53,7 \%$ \\
\hline
\end{tabular}

Source: Processed Research Data, 2019.

The table shows a significance value of 0,00 smaller than 0.05 , which means the data are normally distributed, beside $\mathrm{X}-\mathrm{Y}_{3}$ and $\mathrm{X}-\mathrm{Y}_{5}$. The table also shows that the value can be used to measure dependent variable and independent variable. So, coefficient of determination values proves that advertising message $(\mathrm{X})$ has significant effect towards $\mathrm{Y}_{1}$ perception of $39,1 \%$. Advertising message $(X)$ has significant effect towards $Y_{2}$ emotion of 47,2\%. Advertising message $(\mathrm{X})$ has significant effect towards $\mathrm{Y}_{4}$ association of $60,5 \%$. Advertising message (X) has significant effect towards $\mathrm{Y}_{6}$ behavior of $53,7 \%$. Therefore, all $\mathrm{H} 1$ or alternative hypothesis are accepted. Advertising message (X) towards $\mathrm{Y}_{4}$ association has the highest value. So, advertising message toward association from the facet model of effects is the most influential response on the respondent. 


\section{Discussion}

The message consist information or meaning to be conveyed, can be verbal, non-verbal or through symbols [2]. The structure and attractiveness of the message is very important to be used to determine the effectiveness of the message in the ad. WWF Indonesia's Instagram ad version of FaceApp on the @wwf_ind account consists of non-verbal messages in the form of WWF visual logos, plastic trash photos, and text "FaceApp doesn't work on plastic". WWF Indonesia conveys the message that plastic waste cannot be changed just like a face using FaceApp, an artificial intelligence-based photography application that was viral on social media. One-sided messages only mention positive attributes or benefits, two-sided messages present the good and bad points [4]. The message on the WWF Indonesia ad version of FaceApp was conveyed by showing the negative side of plastic waste that displays visual messages of some photos of plastic waste that the audience usually sees every day, namely plastic bags, plastic bottles and plastic cups. Text messages "FaceApp doesn't work on plastic" indirectly also educate the audience about plastic waste that cannot be changed in a short time, and the WWF logo as a non-profit organization in the environmental field that is already popular in the world. On the other hand, fear appeal is the message strategy used in the FaceApp version of the WWF Indonesia ad, because the text message directly scares the audience about the dangers of plastic waste that cannot be decomposed for a very long time and endanger human life. Fear is an emotion response to a threat that expresses or at least implies some sort of danger [4]. Fear appeal will arouse the audience to take steps to remove the threats.

An effective message has a diamond-like quality that represents how the message effects work together to create the desired consumer response [5]. The message on WWF Indonesia's Instagram advertisement is based on the structure and attractiveness of the message affecting the consumer response measured using The Facet model of effects. The advertisement will be effective if it meets the facet model of effects that has six types of consumer responses. There are perception, emotion cognition, association, persuasion and behavior. Based on the results of the research that has been described previously that each there is an influence of the WWF Indonesia Instagram ad message FaceApp version of Perception, Emotion, Association and Behavior. Perception is the process with the audience received information through five senses [5]. Audience receives messages by viewing FaceApp WWF Indonesia ads through the exposure and selection process. Audience has an interest and interest in plastic waste messages delivered by WWF Indonesia. They also know, are aware and have curiosity when they see non-verbal messages on Instagram @wwf_ind FaceApp version.

Emotion is the sign of effective advertisement. The term of affective (emotion) describes as something that stimulates wants, touches the emotions, establishes a mood, creates liking and elicits feelings [5]. Through WWF Indonesia's Instagram ad message version FaceApp fosters desires and desires with a feeling of pleasure to reduce plastic waste in daily life. They also got carried away and liked the message conveyed by the non-profit organization in the environmental field of WWF Indonesia. Association facet is communication technique through symbols [5]. The goal is to use symbolic connections to define a brand. WWF Indonesia's advertising message that displays several visual messages of photos of plastic waste directly shows the symbol of the danger of plastic waste to the environment. It is also a lesson for the audience to reduce plastic waste in daily life, so that the audience can slowly change a more positive lifestyle without plastic. Through the FaceApp message that it doesn't work on plastic in its Instagram adverts, WWF Indonesia makes the audience to find out more clearly about plastic waste, sharing it with friends, family, and colleagues about the plastic 
waste reduction campaign carried out by WWF Indonesia to prevent the danger of garbage plastic that cannot be decomposed in a short time.

The effects can vary in importance with some campaigns more focused on one or several of the facets [5]. Apart from the data that is not normally distributed on cognition and persuasion so that the hypothesis of its significant influence cannot be proven, the effects of the FaceApp Indonesian version of the WWF advertising message on Instagram remain varied in their effects on perception, emotion, association and behavior. The message effect has the most influence on association. Image WWF Indonesia is very positive for the audience, thereby increasing their connection with WWF Indonesia as a non-profit organization engaged in the environmental field.

\section{Conclusion}

Based on the results and previous discussion about the impact of digital advertising message WWF Indonesia's Instagram advertising FaceApp version on@wwfid toward consumer responses based on The Facet model of effects through questionnaires distributed to 100 respondents, it was concluded that there were significant variables of digital advertising message $(\mathrm{X})$ affect the perception $\left(\mathrm{Y}_{1}\right)$ by $39,1 \%$, the emotion $\left(\mathrm{Y}_{2}\right)$ by $47,2 \%$, the association $\left(\mathrm{Y}_{4}\right)$ by $60,5 \%$ and the behavior $\left(\mathrm{Y}_{6}\right)$ by $53,7 \%$, while the effect of digital advertising messages on the cognition $\left(\mathrm{Y}_{3}\right)$ and persuasion $\left(\mathrm{Y}_{5}\right)$ cannot be proven because the data are not normally distributed, so the test of linear regression cannot be continued.

\section{References}

[1] Bizinsight, "Di 2019, Indonesia Berpotensi Puncaki Pertumbuhan Pasar Digital Advertising," Telkomsel DigiAds, para. 1, February 15, 2019. [Online]. Available: https://digiads.co.id/blog/news/digital-advertising-indonesia-2019/. [Accessed: 12-Sep-2019].

[2] J. Clement, "Number of monthly active Instagram users from January 2013 to June 2018 (in millions)," Statista, $2019 . \quad$ [Online]. Available: https://www.statista.com/statistics/253577/number-of-monthly-active-instagram-users/.

[Accessed: 01-Sep-2019].

[3] S. W. Littlejohn, Theories of Human Communication. Boston, Massachusetts. USA: Wadsworth Thomson Learning, 2002.

[4] B. Belch; E, Goerge; Michel, Advertising \& Promotion: An Integrated Marketing Communications Perspective. New York: McGraw-Hill Education, 2018.

[5] S. E. Moriarty, N. Mitchell, W. Wells, and S. E. Moriarty, Advertising \& IMC: principles \& practice. Pearson Upper Saddle River, NJ, 2012.

[6] L. W. Neuman, Social Research Methods Qualitative and Quantitative Approaches. Boston: Allyn and Bacon, 2000.

[7] K. F. Punch, Introduction to social research: Quantitative and qualitative approaches. sage, 2013.

[8] S. S. Uyanto, "Pedoman analisis data dengan SPSS," Yogyakarta Graha Ilmu, vol. 282, 2009. 